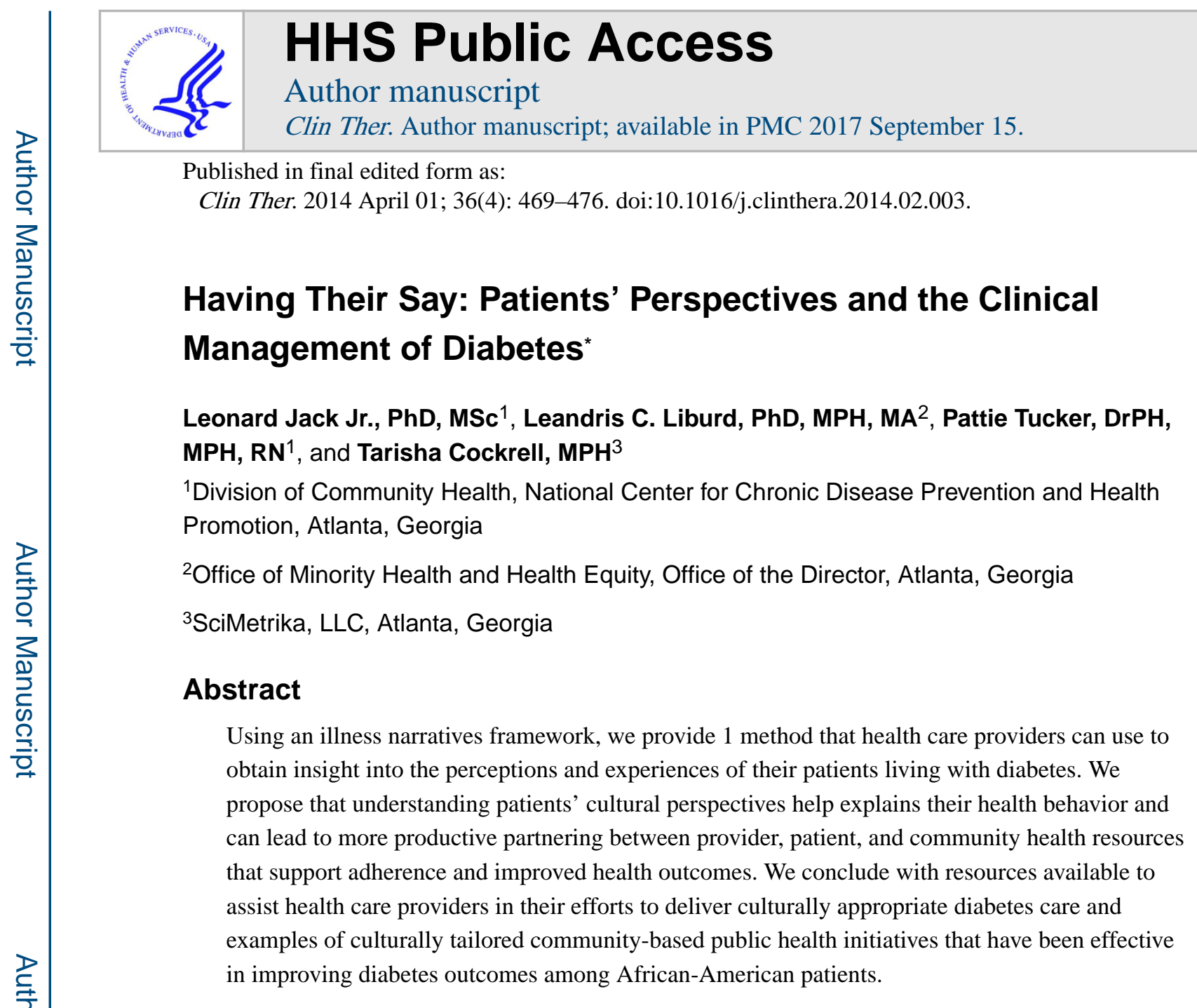

\title{
INTRODUCTION
}

According to the International Diabetes Federation, 382 million people worldwide were estimated to have diabetes in 2013 and this number is expected to rise to 592 million by 2035. "Socially and economically disadvantaged people in every country carry the greatest burden of diabetes and are often the most affected financially." In the United States, diabetes is more common among certain racial and ethnic groups, particularly AfricanAmerican, Hispanic, and Native-American subjects. ${ }^{1,3}$

In this commentary, we describe the burden of diabetes in the United States, paying particular attention to its impact among African-American patients. To facilitate the delivery of high-quality health care to African-American patients with diabetes, we shifted the traditional focus away from clinical interventions to an exploration of the cultural and psychosocial factors that influence diabetes prevention and control. ${ }^{4-6}$ Our goal was to

\footnotetext{
* The findings and conclusions in this report are those of the authors and do not necessarily represent the official position of the Centers for Disease Control and Prevention.

Address correspondence to: Leonard Jack, Jr., PhD, MSc, Division of Community Health, National Center for Chronic Disease and Health Promotion, 4770 Buford Highway, Mail Stop F-81, Atlanta, GA 30341. ljack@cdc.gov. 
inspire greater attention from health care providers to the cultural context that both supports and undermines diabetes self-management. Using an illness narratives framework, we provide 1 method that health care providers can use to obtain insight into the perceptions and experiences of their patients living with diabetes. ${ }^{7}$ We propose that understanding patients' cultural perspectives help explain their health behavior and can lead to more productive partnering between provider, patient, and community health resources that support adherence and improved health outcomes. We conclude with resources available to assist health care providers in their efforts to deliver culturally appropriate diabetes care, as well as examples of culturally tailored community-based public health initiatives that have been effective in improving diabetes outcomes among African-American patients.

\section{TYPE 2 DIABETES AMONG AFRICAN-AMERICAN PATIENTS}

According to the Centers for Disease Control and Prevention, African-American adults are twice as likely to have been diagnosed with diabetes by a physician than their non-Hispanic white counterparts. ${ }^{3}$ African-American patients typically experience higher rates of complications, such as lower extremity amputations, kidney failure, cardiovascular disease, and blindness. ${ }^{1}$ For example, in 2008, African-American men were 2.7 times as likely to start treatment for diabetes-related end-stage renal disease compared with non-Hispanic white men. ${ }^{4}$ Diabetes can adversely affect both psychosocial and neurocognitive functioning. ${ }^{5}$ Preventing or delaying microvascular and macrovascular diseases requires the individual to accept the need to maintain several self-care behaviors. ${ }^{6}$ These self-care behaviors can include blood glucose monitoring, nutrition and physical activity, foot care, coping, problem solving, insulin and other drug therapies (where appropriate), and health care-seeking behaviors. The difficulty of adhering to and maintaining a prescribed diabetes management regimen has been documented over the years among persons with diabetes. ${ }^{7}$ This helps to explain why diabetes has been described as one of the most complex and demanding chronic diseases.

\section{CULTURALLY COMPETENT DIABETES CARE}

Diabetes, if not managed properly, can negatively affect quality of life. ${ }^{1}$ The absence or lack of any of the previously mentioned self-management behaviors can greatly impact clinical outcomes (eg, glycosylated hemoglobin) and psychological well-being (eg, stress, selfesteem, depression). ${ }^{5}$ The role of stress, depression, coping, and cultural beliefs has received attention as powerful psychosocial determinants in the clinical management and progression of diabetes. ${ }^{8-10}$ These psychosocial factors, in combination with reported risk factors such as obesity, sedentary lifestyle, and family history, collectively increase one's risk of developing diabetes and its associated complications. Furthermore, the role of the environment, both physical (eg, access to healthy foods, options for physical activity, neighborhood safety) and social (eg, family and social support, resources at the workplace to facilitate diabetes management), contributes to cultural norms, views, and perspectives of individuals. ${ }^{11}$

Diabetes prevention and control can also be understood within the context of one's ethnic identity. Ethnic identity has been defined as "an individual's sense of identification with a 
particular ethnic group and its beliefs, values, norms, and history." 12 Ethnic identity is a cultural factor that may influence a person's health care choices, including preferences for physicians from specific ethnic backgrounds, perceptions of discrimination in health care settings, and ways of coping with chronic illness. African-American ethnic identity is shaped from the individual's personal perspectives and social networks (internal) and through societal structures and norms (external). Thus, ethnic identity can be formed in response to discriminatory practices and historical exclusion of this population group, as well as in opposition to other ethnic groups, and on the basis of traditions defined within the culture. Although there are intragroup variations in ethnic identity among African-American patients, ethnic identity can also serve as a protective factor that may positively influence health outcomes. Cross and Strauss ${ }^{13}$ argue that a person with a stronger African-American identity may be able to protect self-esteem and maintain a sense of perspective and personal worth in the face of racism or unconscious bias experienced in the health care setting.

These perspectives and others establish rules for living that extend to the cultural meaning of disease and its management (eg, physical activity, medication use, health care- seeking behaviors, patient-provider interactions). ${ }^{14}$ Culture norms profoundly affect the way people define and experience health and disease. They also influence adherence to diet and insulin therapy and, ultimately, glycemic control. ${ }^{10,14}$ Similarities and differences between and among ethnic groups are manifested in life experiences, family backgrounds, individual beliefs, attitudes, practices, socioeconomic status, environmental surroundings, and perceptions and experiences of racism. ${ }^{10,11,14}$ These similarities and differences must be understood and considered when designing, delivering, and evaluating primary or secondary prevention lifestyle interventions. This is particularly the case given that culturally appropriate interventions (clinical and community) greatly affect adoption and maintenance of healthy behaviors over time. ${ }^{13}$ For example, exposing patients to culturally tailored diabetes education, the cornerstone of effective diabetes management, is central to improving self-efficacy and patient empowerment. ${ }^{10,14}$

Hence, improving self-efficacy and patient empowerment is more complex among AfricanAmerican patients (and other racial and ethnic groups) than narrowly focusing on medication adherence, a self-care behavior emphasized and promoted by health care providers as being central to managing diabetes. ${ }^{5}$ A lack of understanding in this regard among some health care providers can lead to bias in clinical decisions concerning diagnostic and treatment options offered or provided to racially and ethnically diverse patients. How health care providers view and interact with patients of various racial and ethnic backgrounds is influenced by cultural beliefs about why patients behave in a particular manner. Better understanding patients' cultural perspectives through illness narratives can offer an important additional lens to explain patient behavior and improve patient-provider communication and interactions.

\section{ILLNESS NARRATIVES}

Although health care providers are often principally concerned with disease management, patients may contemplate their disease more broadly within an illness framework. ${ }^{1}$ Disease management tends to be limited to efforts to correct "abnormalities in the structure and/or 
function of organs and organ systems; pathological states whether or not they are culturally recognized." Illness, however, is described as "how the sick person and members of their family or wider social network perceive, live with, and respond to symptoms and disability." ${ }^{3}$ How illness is perceived is culturally constructed and has meaning, and these meanings have implications for successful diabetes management.

Borrowing from an earlier published study, ${ }^{15}$ we describe illness narratives as one strategy for closing the knowledge gap between patients and providers regarding patients' perspectives related to the clinical management of diabetes. The disease-illness distinction is well established in applied medical anthropology. Arthur Kleinman, a prominent American psychiatrist and professor of medical anthropology and cross-cultural psychiatry at Harvard University, proposes questions in 5 broad anthropologic categories (Table I) that allow providers to gain a deeper understanding of patients' views and the social, spiritual, and psychological realities of dealing with an illness. ${ }^{7}$ Kleinman describes these categories as life history, patient and family explanatory models, symptom symbols, personal and interpersonal significance, and culturally marked disorder.

Life histories are brief synopses of individuals' lives that include their "major continuities and changes in attitude, personality, major life goals and obstacles, and relevant earlier experiences of coping with illness and other serious conditions." A diagnosis of diabetes is a significant life event that causes patients to re-examine their life, behaviors, and future plans and options. Patient and family explanatory models are informal descriptions of the occurrence of a particular illness. Exploring with patients why they believe they developed diabetes reveals important differences between the biomedical understanding of disease etiology and indigenous views of disease causation. Patients may be less likely to follow clinical recommendations if they do not accept clinical explanations of what is occurring in their body. Symptom symbols are "accepted forms of knowledge about the body, the self, and their relationship to each other and to the more intimate aspects of our worlds." patients interpret changes in their bodies and whether these changes code (signal) a serious chronic disease or a condition that can be quickly resolved likely has implications for how they use the health care system, how and what medications they take, and their general orientation to preventive health care practices. Personal and interpersonal significance involves factors external to the individual and how these factors influence an individual's experience of living with an illness. Having diabetes can affect one's employability and job security, sexual functioning, and other social relationships. Moreover, changing one's lifestyle in the interest of managing the disease and the impact of diabetes complications on one's ability to meet routine obligations affect spouses, siblings, coworkers, and others, as well as the person with diabetes. The personal and interpersonal consequences of having diabetes can be profound. A culturally marked disorder is the assignment of an illness as not normal. How common or normal an illness is perceived to be depends on the social context and time period. Whether an illness is perceived as common can also be influenced by race and ethnicity, socioeconomic status, and other social characteristics. For example, participants in a community-based diabetes program in the southeastern part of the United States shared that people often hid the fact that they had diabetes to avoid being alienated and misrepresented by community members who did not understand the disease or its management. 
In some instances, people with diabetes and their health care providers share similar understandings of the aforementioned anthropologic categories. ${ }^{15}$ Divergence in patient and provider views, however, offers an opportunity to explore and gather essential information necessary to facilitate effective patient counseling and diabetes self-management.

\section{CASE STUDY}

Margaret is a 60-year-old African-American woman with type 2 diabetes diagnosed 15 years ago. She is the single mother of 1 son who is 44 years old. His name is George, and he has an intellectual disability. Margaret had to drop out of high school after George was born. She lives alone and gets most of her information about what is going on in her community and nationally from television and cable news shows. She receives health care from the diabetes clinic at a nearby academic health center. She drinks a tablespoon of vinegar every day to "cut the sugar in her blood," takes her medications as prescribed, and eats a traditional Southern diet that is high in salt, fat, and sugar. She does not work outside the home or engage in any physical activity. In fact, she spends most of her days indoors, seated at the kitchen table, watching people pass by as she looks out of her kitchen window. George drops by every evening as he is headed home from work. He occasionally joins his mother for dinner. Rice is always included in the meal.

Margaret was recently diagnosed with advanced diabetic retinopathy. She is terrified at the thought of losing her eyesight and equally fearful of laser surgery, which was described by her physician as "zapping" the weak blood vessels in her eye. What conversation will you have with Margaret?

\section{CULTURALLY TAILORED PATIENT-PROVIDER AND COMMUNITY HEALTH INITIATIVES}

When patients leave their physicians' offices, they can and often veto recommendations offered by health care providers. The case study presented in this commentary illustrates the importance of health care providers engaging in ongoing conversations with patients to learn more about the many contextual factors influencing diabetes management. Kleinman's illness narrative offers health care providers a strategy that can be used to facilitate ongoing patient-provider interactions. ${ }^{7}$ We acknowledge that although patient- provider interactions are important, they should and can be executed in concert with health care and communitydriven interventions designed to address diabetes health disparities. Such interventions, in addition to patient-provider interactions, have the potential to address social and cultural realities and to improve health behaviors and outcomes among African-American patients. ${ }^{10}$ Although an exhaustive review of the literature is beyond the scope of this commentary, we provide examples of successful health care and community-driven interventions in improving health outcomes among African-American patients.

Peek et al ${ }^{16}$ published a systematic review of health care interventions that focused on patients, providers, and health systems addressing disparities in diabetes health. The systematic review included patients within health care organizations that offered culturally tailored interventions to specific racial/ethnic populations. ${ }^{16}$ For example, Anderson-Loftin 
et al ${ }^{17}$ used a culturally competent approach to examine the effects of a dietary selfmanagement intervention on physiologic outcomes and dietary behaviors among AfricanAmerican patients living with type 2 diabetes. The study included 97 adult AfricanAmerican patients with type 2 diabetes living in rural South Carolina. Study participants referred by their primary physician were randomly assigned to either usual care (referral to a traditional diabetes class, instructions about the nature and complications of diabetes, and telephone contact at 3 months by a research assistant) or the intervention group (included culturally tailored sessions on low-fat dietary strategies, peer-professional group discussions, and telephone follow-up by a nurse case manager). This intervention reflected the values, beliefs, food preferences, health care practices, and learning methods of southern AfricanAmerican patients. Such an approach resulted in statistically significant changes in the intervention group, including lowered body mass index and improved dietary fat behaviors.

Another culturally tailored approach by Keyserling et $\mathrm{al}^{18}$ included an intervention designed to address the psychosocial, cultural, and economic needs of low-income African-American women with type 2 diabetes. The study was conducted in central North Carolina at several community health centers, a health maintenance organization, and an academic health center's general medicine clinic. Two hundred African-American women aged $\geq 40$ years were randomly assigned to 1 of 3 intervention groups: A, clinic and community $(n=67)$; B, clinic only $(n=66)$; or $C$, minimal care $(n=67)$. The clinic-based intervention groups (A and $\mathrm{B}$ ) received tailored counseling on physical activity and dietary intake from a nutritionist; the community-based intervention group (A) participated in group sessions and monthly telephone calls from a peer counselor to provide social support and emphasize the behavior change goals; and the minimal intervention group (C) participants were mailed educational pamphlets. At the 6- and 12- month follow-up visits, group A participants were found to be $15 \%$ more active that group $\mathrm{C}$ participants. These findings suggest that a culturally tailored clinic- and community-based intervention program, focused primarily on moderate-intensity activities, can lead to increased physical activity of African-American women with type 2 diabetes. ${ }^{18}$ These and other community examples demonstrate that patient-focused culturally tailored diabetes self-management and support programs can greatly improve healthy behaviors and health outcomes among African-American patients.

\section{DIABETES RESOURCES}

Several government and national nonprofit organizations provide accessible patient- and provider-focused resources on diabetes self-management and culturally competent care. ${ }^{19} \mathrm{~A}$ shortened list of organizations providing Web-based diabetes prevention and control resources appear in Table II. These organizations include 1 national nonprofit group (American Diabetes Association), ${ }^{20}$ a federal agency (the US Department of Health and Human Services Office of Minority Health), ${ }^{21}$ and a federally sponsored initiative (the National Diabetes Education Program). ${ }^{22}$ All of these organizations offer culturally appropriate resources and support. For example, the American Diabetes Association's DiabetesPro Web site ${ }^{20}$ contains links to several resources for health care professionals working with individuals living with diabetes. The 2014 Standards of Medical Care in Diabetes and Resources for Professionals are 2 links that address cultural factors and culturally appropriate diabetes self-management education and support. The US Department 
of Health and Human Services Office of Minority Health Think Cultural Health initiative is based on the National Standards for Culturally and Linguistically Appropriate Services in Health and Health Care. These national standards are designed for individuals and health care organizations to implement culturally and linguistically appropriate services. The Think Cultural Health Web site has several components, including A Physician's Practical Guide to Culturally Competent Care, which is a continuing medical education resource for health care professionals to earn up to 9 credit or contact hours on cultural competency in health care. ${ }^{21}$ The federally sponsored National Diabetes Education Program Practice Transformation for Physicians and Health Care Teams Web site provides health care professionals with clinical practice tools and low-cost culturally and linguistically appropriate diabetes selfmanagement education and support materials for African-American patients. This site has several elements, including Improve Practice Quality and Enhanced Patient-Centered Interactions sections. ${ }^{22}$

\section{CONCLUSIONS}

Helping African-American patients manage their diabetes will require a collaborative care approach. Healthcare providers must be able to provide culturally tailored health messages and counseling that aligns with the social and cultural norms of African-Americans.

Kleinman's framework offers healthcare providers five anthropologic categories. These five categories can assist healthcare providers in understanding factors impacting the realities of African-Americans living with diabetes. Healthcare providers are encouraged to integrate this approach into their everyday practice. In do so, healthcare providers will enhance their ability to serve as culturally competent practitioners and tremendous supporter to their patients.

\section{Acknowledgments}

Dr. Jack was responsible for the literature search and writing of the manuscript. Dr. Liburd was responsible for the literature search, creation of Table I, and writing of the manuscript. Dr. Tucker was responsible for the literature search, creation of Table II, and writing of the manuscript. Dr. Cockrell was responsible for the literature search and reference formatting.

\section{References}

1. International Diabetes Federation. IDF Diabetes Atlas. 6thhttp://www.idf.org/diabetesatlas. Accessed January 3, 2014

2. International Diabetes Federation. IDF Diabetes Atlas. 6thhttp://www.idf.org/sites/default/files/ EN_6E_Atlas_Full_0.pdf. Accessed January 3, 2014

3. Centers for Disease Control and Prevention. Summary Health Statistics for US Adults: National Health Interview Survey, 2010. Vital and Health Statistics. 2012; 10:38-39. http://www.cdc.gov/ nchs/data/series/sr_10/sr10_252.pdf. Accessed January 3, 2014.

4. Centers for Disease Control and Prevention. Diabetes Interactive Atlas and National Surveillance Data-Diabetes Complications-End-Stage Renal Disease (ESRD). http://www.cdc.gov/diabetes/ statistics/esrd/fig5.htm. Accessed January 3, 2014

5. Delamater AM, Jacobson AM, Anderson B, et al. Psychosocial therapies in diabetes: report of the Psychosocial Therapies Working Group. Diabetes Care. 2001; 24:1286-1292. [PubMed: 11423517]

6. Tomky D, Cypress M, Dang D, et al. AADE7 self-care behaviors. Diabetes Educ. 2008; 34:445449. [PubMed: 18535317] 
7. Kleinman, A. The Illness Narratives: Suffering Healing and the Human Condition. New York, NY: Basic Books; 1988.

8. Jack L, Airhihenbuwa C, Namaeyo-Funa A, et al. The psychosocial aspects of diabetes care. Using collaborative care to manage older adults with diabetes. Geriatrics. 2004; 59:26-31.

9. Golden SH, Lazo M, Carnethon M, et al. Examining a bidirectional association between depressive symptoms and diabetes. JAMA. 2008; 299:2751-2759. [PubMed: 18560002]

10. Jack L, Satterfield D, Rodriquez B, et al. Cultural sensitivity and diabetes education: recommendations for diabetes educators. Diabetes Educ. 2007; 33:41-44. [PubMed: 17272791]

11. Jack L, Jack N, Haynes S. Social determinants of health in minority populations: a call for multidisciplinary approaches to eliminate diabetes-related health disparities. Diabetes Spectrum. 2012; 25:9-13.

12. Jones, H., Liburd, L. Reversing the tide of type 2 diabetes among African-Americans through interdisciplinary psychology and medical anthropology research. In: Freudenberg, N.Klitzman, S., Saegert, S., editors. Urban Health and Society: Interdisciplinary Approaches to Research and Practice. 1st. San Francisco, Calif: Jossey-Bass; 2009. p. 278-279.

13. Cross, WE., Strauss, L. The everyday functions of African-American identity. In: Swim, JK., Stangor, C., editors. Prejudice: The Target's Perspective. San Diego, Calif: Academic Press; 1998. p. 267-279.

14. Goode TD, Haywood SH, Wells N, Rhee K. Family-centered, culturally, and linguistically competent care: essential components of the medical home. Pediatr Ann. 2009; 38:505-512. [PubMed: 19772237]

15. Liburd LC, Namageyo-Funa A, Jack L, et al. Views from within and beyond: illness narratives of African-American men with type 2 diabetes. Diabetes Spectrum. 2004; 17:219-224.

16. Peek ME, Cargill A, Huang ES. Diabetes health disparities: a systematic review of healthcare interventions. Med Care Res Rev. 2007; 64(Suppl 5):101s-156s. [PubMed: 17881626]

17. Anderson-Loftin W, Barnett S, Bunn P, et al. Soul food light: culturally competent education. Diabetes Educ. 2005; 31:555-563. [PubMed: 16100331]

18. Keyserling TC, Samuel-Hodge CD, Ammerman BE, et al. A randomized trial of an intervention to improve self-care behaviors of African-American women with type 2 diabetes. Diabetes Care. 2002; 25:1576-1583. [PubMed: 12196430]

19. Rivera, MD., Tucker, PJ. Community change: its importance in evaluating diabetes programs in communities of color. In: Liburd, LC., editor. Diabetes and Health Disparities: Community-based Approaches for Racial and Ethnic Populations. 1st. New York, NY: Springer; 2010. p. 169-209.

20. American Diabetes Association. DiabetesPro Professional Resources Online. http:// professional.diabetes.org/ResourcesForProfessionals.aspx?cid=84160. Accessed January 6, 2014

21. US Department of Health and Human Services Office of Minority Health. Think Cultural Health. https://www.thinkculturalhealth.hhs.gov/index.asp. Accessed January 6, 2014

22. US Department of Health and Human Services National Diabetes Education Program. Practice Transformation for Physicians and Healthcare Teams. http://ndep.nih.gov/hcp-businesses-andschools/HealthCareProfessionals.aspx. Accessed January 6, 2014 


\section{Table I}

\section{Illness narrative framework.}

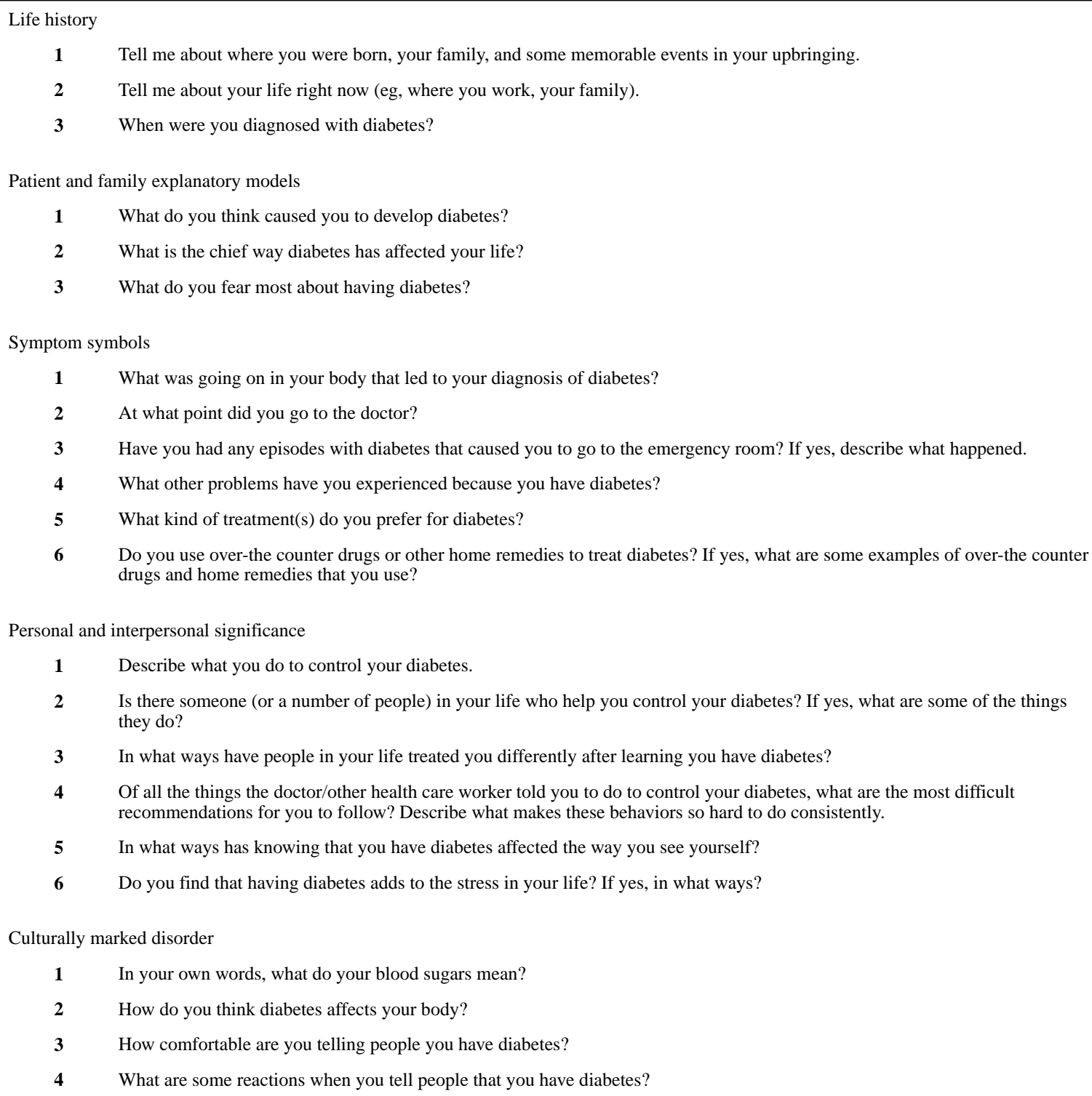

4 Of all the things the doctor/other health care worker told you to do to control your diabetes, what are the most difficult recommendations for you to follow? Describe what makes these behaviors so hard to do consistently.

$5 \quad$ In what ways has knowing that you have diabetes affected the way you see yourself?

6 Do you find that having diabetes adds to the stress in your life? If yes, in what ways?

Culturally marked disorder

1 In your own words, what do your blood sugars mean?

$2 \quad$ How do you think diabetes affects your body?

$3 \quad$ How comfortable are you telling people you have diabetes?

$4 \quad$ What are some reactions when you tell people that you have diabetes? 


\section{Table II}

Evidence-based resources for health care providers delivering culturally appropriate care to people living with or at risk for diabetes.

\begin{tabular}{|c|c|c|}
\hline $\begin{array}{l}\text { Government } \\
\text { and National } \\
\text { Nonprofit } \\
\text { Organizations }\end{array}$ & $\begin{array}{l}\text { Description of Diabetes Health } \\
\text { Professional Resource }\end{array}$ & Web Site \\
\hline $\begin{array}{l}\text { American } \\
\text { Diabetes } \\
\text { Association } \\
\text { (ADA) }\end{array}$ & $\begin{array}{l}\text { ADA DiabetesPro Clinical Practice } \\
\text { Recommendations includes screening, } \\
\text { diagnostic, and treatment methods found } \\
\text { to or have potential to favorably affect } \\
\text { health outcomes of individuals living } \\
\text { with diabetes. The Resources for } \\
\text { Professionals provides educational tools } \\
\text { for both providers and patients, with links } \\
\text { to diabetes education resources such as } \\
\text { slide presentations, toolkits with provider } \\
\text { and patient materials, and multimedia } \\
\text { self-learning tools. }{ }^{20}\end{array}$ & http://professional.diabetes.org/ResourcesForProfessionals.aspx?cid=84160 \\
\hline $\begin{array}{l}\text { US Department } \\
\text { of Health and } \\
\text { Human Services } \\
\text { Office of } \\
\text { Minority Health }\end{array}$ & $\begin{array}{l}\text { Think Cultural Health is founded on the } \\
\text { National Standards for Culturally and } \\
\text { Linguistically Appropriate Services in } \\
\text { health and health care. This site offers } \\
\text { resources and tools to promote cultural } \\
\text { and linguistic competency in health care. } \\
\text { A Physician's Practical Guide to } \\
\text { Culturally Competent Care is a free, } \\
\text { online accredited educational program for } \\
\text { physicians, physician assistants, and } \\
\text { nurse practitioners. It is designed to equip } \\
\text { health care professionals with the } \\
\text { knowledge and skills needed to provide } \\
\text { respectful, understandable, and effective } \\
\text { services. }^{21}\end{array}$ & https://cccm.thinkculturalhealth.hhs.gov/ \\
\hline $\begin{array}{l}\text { National } \\
\text { Diabetes } \\
\text { Education } \\
\text { Program }\end{array}$ & $\begin{array}{l}\text { The Practice Transformation for } \\
\text { Physicians and Health Care Teams site } \\
\text { offers models, links, tools, and resources } \\
\text { to assist health care professionals in their } \\
\text { initial and continued efforts to improve } \\
\text { the quality of their health care practice } \\
\text { and their health care delivery systems. } \\
\text { This site's content is based on current } \\
\text { diabetes prevention and control peer- } \\
\text { reviewed literature and evidence-based } \\
\text { clinical practice recommendations. }{ }^{22}\end{array}$ & http://ndep.nih.gov/hcp-businesses-and-schools/HealthCareProfessionals.aspx \\
\hline
\end{tabular}

